\title{
Research on the Digital Transformation of Sporting Goods Manufacturing Industry in China Based on "C2M" Mode
}

\author{
Ji Zhu, Jianye Liu* \\ Sports Reform and Development Research Center, Institute of physical education, Henan University, \\ Kaifeng 475001, Henan, China \\ *Corresponding Author.
}

\begin{abstract}
This paper studies the transformation and upgrading of sporting goods manufacturing industry in China, and discusses why the sporting goods manufacturing industry needs digital transformation from the perspective of "C2M" mode, and puts forward some suggestions on how to carry out the digital transformation of sporting goods manufacturing industry in China based on the "C2M" mode. Based on the "C2M" mode, four suggestions are put forward: first is to establish a platform to attract consumers and meet the personalized customization needs to face the gradual diversification of consumer needs; second is to build a flexible production chain and change the business management concept to face the gradual increase in the cost of production factors; third is to accelerate the digital transformation of management and improve the level of management modernization to face the drawbacks brought by the industry from design to sales and circulation; fourth is to strengthen brand building and pursue market segmentation in order to face the situation that China's large-scale sporting goods manufacturing industry is facing high marketing expenses and the small and medium-sized sporting goods manufacturing industry does not pay attention to innovation.
\end{abstract}

Keywords: C2M mode, sporting goods manufacturing, digital transformation

The general office of the state council of the people's republic of China issued the "opinions on promoting national fitness and sports consumption to boost the high-quality development of the sports industry" in 2019, pointing out that it supports the innovative development of the sporting goods manufacturing industry, which refers to promote the application of emerging technologies such as intelligent manufacturing, big data, and artificial intelligence in the field of sports manufacturing. According to the white paper on the development of digital economy in China 2020, China's digital economy accounted for $36.2 \%$ of GDP in 2019, and four aspects of China's digital economy development were proposed: digital industrialization, industrial digitization, data governmentation, and data valuation. According to the "announcement on the total scale and value added of the national sports industry in 2019" jointly issued by the national bureau of statistics and the general administration of sport of China, sporting goods and related manufacturing accounted for $46.2 \%$ of the national sports industry. As an important part of China's sports industry, sporting goods manufacturing industry should seize the opportunity to keep up with the era and industrial digitization. However, the problem of how China's sporting goods manufacturing industry embraces digitization and promotes digital transformation is becoming more and more prominent. This paper will analyze the internal problems of China's sporting goods companies, and put forward a concrete plan on digital transformation of China's sporting goods manufacturing industry based on the "C2M" mode.

\section{Meaning and Research Status of "C2M" Mode}

1.1 Meaning of "C2M" mode

C2M mode is also called short circuit economy. That is, customer to manufacturer, $\mathrm{C}$ represents customer, and $\mathrm{M}$ represents manufacturer. With the background of the Industrial Internet, it has the characteristics of informatization,

ISSN: 0010-8189

(c) CONVERTER 2020

www.converter-magazine.info 
intelligentization and technicalization. C2M mode directly connects consumers and production to meet consumers' needs; adopts order-based marketing methods to achieve zero product inventory; uses standard digitization production processes to ensure the lowest production costs and the shortest production cycle. The "C2M" mode gets rid of the traditional M-to-C industry chain mode, and the industry chain has undergone essential changes. Both the $\mathrm{M}$-side and the $\mathrm{C}$-side have put forward new requirements to carry out the transformation and upgrading. The author believes that China's "C2M" mode is more inclined to the digital transformation of manufacturing based on the industrial Internet, to meet the individual needs of consumers, and achieve large-scale private customization ultimately.

\subsection{Research status}

Searching related topics such as "Sporting Goods Manufacturing", "C2M Mode", "Digital Transformation", "Digital Economy", "Sports Industry" on CNKI, some papers were found. Ren Bo and Huang Haiyan published "The Dynamic Mechanism and Mode of the Integration of China's Digital Economy and Sports Industry", which thought that the penetration and integration of the digital economy and the sporting goods manufacturing industry will produce new modes: full-process production mode and customized production mode. Song Ying, etc. [1] published "New Ideas for Manufacturing Reform under the C2M Mode", which believed that in view of the dilemma faced by manufacturing companies moving toward the $\mathrm{C} 2 \mathrm{M}$ mode, it is necessary not only to encourage manufacturing companies to strengthen the construction of modularization to achieve unlimited segmentation of products' sub-modules and unlimited combinations of final products, but also to help companies build a personalized experience platform, promote companies to build a decentralized, de-hierarchical management organization structure, and automatically optimize and adjust enterprise operating mechanisms. Chen Qingmei published "Research on the Strategy of C2M E-commerce Mode Helping the Transformation and Upgrading of Traditional Manufacturing Enterprises", which proposed that under the C2M mode, manufacturing companies should start from the aspects of information platform construction and flexible production and combine "universal" unit modules with "special" customization, so as to achieve a win-win situation that meets the individual needs of customers and brings large-scale economic benefits to the company. In summary, the integration of the digital economy and the sports industry has attracted the attention of experts and scholars, especially since the outbreak of COVID-19. Research on the digital transformation of the sporting goods manufacturing industry has begun to take shape, and there are also quite a few studies on the transformation of the manufacturing industry based on the "C2M" mode. However, research on the digital transformation of China's sporting goods manufacturing industry based on the "C2M" mode is not seen. This paper believes that the main problems of China's sporting goods manufacturing industry should be clarified, and the corresponding solutions on the digital transformation of China's sporting goods manufacturing industry should be put forward based on the "C2M" mode.

\section{Current Industry Status under "C2M" mode}

2.1 Traditional e-commerce platform energizing manufacturing industry to improve digital transformation ability

Traditional e-commerce platforms, mainly based on Alibaba, JD.com, Taobao and Suning, are energizing the upstream manufacturing to speed up their digital transformation. Through the combination of traditional manufacturing and new technologies including AR, VR, big data, cloud computing, artificial intelligence, blockchain, and 5G, new opportunities have emerged to make traditional manufacturing's industrial chain more intelligent. Traditional e-commerce platforms rely on consumers to generate a large amount of consumption data, and rely on digital capabilities to help the digital transformation of traditional manufacturing, form a closed business loop of upstream and downstream industrial chain, and continue to provide consumers with cost-effective and personalized products. For example, Taobao's "Tiantian Factory" project puts forward the goal of transforming 10,000 digital factories and 100 digital industry belts in three years [2].

ISSN: 0010-8189

(c) CONVERTER 2020 
2.2 Breaking through traditional e-commerce platform and building a vertical e-commerce platform

Biyao Mall is the first electronic commerce platform based on the "C2M" model. The platform provides consumers with a variety of customized services whose product variety is wide and customization level is deep, through various digital technologies. On the manufacturing side, the closed loop of the industrial chain is completed by cooperating with some high-quality ODM companies. The platform has greater control over the price and quality of products. The author believes that Biyao Mall has not broken through the business mode of the traditional e-commerce platform. It allows high-quality ODM companies to settle in, but it doesn't participate in the enterprise digital transformation, or help traditional company brands. At the same time, it has to beware of the threats posed by vertical e-commerce like Lifease [3].

\subsection{Traditional manufacturing industry relying on digital economy to carry out digital transformation}

After more than 10 years of exploration, Red Collar Group in Shandong Province has formed its own unique mode. The production and sales of traditional suits have been changed through its own platform Kutesmart, and its own unique SDE (Source Date Engineering) tool has been created. An on-demand suit can be shipped in one week. Compared with traditional manual work, production efficiency is improved, and the quality is guaranteed, which helps the transformation and upgrading of the enterprise [7-8]. Under this mode, the transformation of the production chain is the most thorough, and at the same time it is good for brand building and unique moat formation. However, the transformation and upgrading often have certain characteristics such as large time span, high cost, and relatively single category, which makes it difficult for medium-sized enterprises to transform and imitate.

\section{Main Problems that China's Sporting Goods Enterprises Facing}

\subsection{Consumers' demand diversifying gradually from the perspective of demand}

With the development of productivity and the improvement of people's living standards, people's demand for sporting goods has gradually diversified. According to the 2019 "Research Report on Internet C2M E-commerce Industry of China's Manufacturing Industry" released by research, when the per capita GDP reaches USD20,000, mass consumption will return to the essence of consumption, and conspicuous consumption will gradually recede. Cost-effectiveness and simple style may become mainstream, indicating that a certain economic foundation has been laid. The main reason for this is that when the $80 / 90$ millennials are worrying about "invisible poverty" due to the high cost of living on the front line, the cost-effective economy has become a rigid demand, leading the personalized demand, and requiring the transformation and upgrading of the production to enhance the ability of small-scale customization. With the influence of technologies such as the Internet, smartphones and tablet computers, Generation Z, rich and carefree, with high-viscosity on online consumption, pursuit of personalized cultural needs, and leading their own unique pursuits, have proposed new demands for China's sporting goods enterprises and brought new opportunities. Professional athletes are more demanding on sporting goods and need a higher degree of customization. A suitable sporting product not only prevent sports injuries but also is an important support for improving athletes' performance. Among cultural, and educational sporting goods, the differences in student groups have led to different specifications for the same item, which requires personalized customization. Economic foundation, consumer groups and consumer preferences, they all raise new issues for China's sporting goods manufacturing industry. Consumer demand is gradually diversifying to promote the transformation and upgrading of China's sporting goods companies [4].

3.2 Production factor costs gradually increasing from the perspective of production

In 1985, Michael Porter proposed the value chain theory. Since the reform and opening up and joining the World Trade Organization, China's sporting goods companies have entered the labor division in the internationalization of

ISSN: 0010-8189

(C) CONVERTER 2020

www.converter-magazine.info 
sporting goods and stayed in the low end of the value chain relying on comparative advantages and production factors such as the huge domestic market, low labor cost and land cost. In May 2020, Xi Jinping proposed to gradually form a development pattern that taking domestic circulation as the main body, and promoting both domestic and international circulation [5]. The value chain of sporting goods companies in China should also be changed accordingly, from GVC (Global Value Chain) to NVC (National Value Chain). The smile curve theory put forward by the president of Taiwan Acer describes the added value of different links in the value chain. Sporting goods are composed of links of research \& development, innovation, processing, production, manufacturing, marketing, branding, and services. Added value is high at both ends and added value is low in the middle. China's sporting goods manufacturing industry is still in the middle of the smiling curve to a large extent, with low added value. Since 2010, China has entered the Lewis turning point, and labor costs have gradually increased. Especially since the COVID-19, the world has stopped working and producing, so that China's raw material prices are facing a high degree of uncertainty. From the international environment to the domestic environment, based on the value chain, China's sporting goods companies are facing huge challenges on production. The low price of labor cost, raw materials and other production factors in the past has gradually increased, making the comparative advantages of China's sporting goods manufacturing industry gradually disappear.

\subsection{Slow circulation from production to sales in view of production}

The traditional industrial chain that integrating raw materials, auxiliary materials, production equipment, mechanical parts, research \& development design, procurement, production and sales will cause certain limitations. The saying "From commodity to currency is a thrilling leap. If it falls, then not only the commodity will be broken, but also the owner of the commodity." from Marx in Das Kapital portrays this relationship to a certain extent. In the view of production, the time span from product processing to selling is large. With the rapid changes in the market, it is difficult for the products produced to meet the trend of the market, which in turn causes products overstock and has a huge impact on the cash flow of enterprises. But for some small and medium-sized enterprises, the success of a product determines the life and death of the enterprise. From the perspective of sales, the quality of the macro economy, the income level of residents, and the bargaining power of channels all have a huge impact on product sales. After the outbreak of COVID-19, the blockade of offline channels has made Li-Ning, Anta and other well-known Chinese sporting goods companies join the ranks of product price reductions, hoping to replace their products with stable cash flow as soon as possible to face the economic downturn caused by the epidemic. At the same time, with the advent of the e-commerce era, it is even more important to build new and diversified online sales channels and to get rid of the era where offline sales channels were king in the past. The faster the circulation of products, the more the circulation and turnover of capital, and the higher the profit of the enterprise. However, the traditional mode faces great limitations from production to sales, and new modes need to be found to avoid this risk [6].

3.4 Huge marketing expenses for china's sporting goods manufacturing industry from the perspective of marketing

Compared with traditional manufacturing, the marketing expenses of China's sporting goods manufacturing industry concentrates mainly in sports sponsorship, and the amount is huge. Taking Li-Ning as an example, Li-Ning signed a five-year sponsorship contract of CNY1 billion with CBA in 2017, which means an annual expenditure of CNY200 million of Li-Ning. Li-Ning sponsors not only CBA, but also decades of sports events and sports teams. It is conceivable that the annual marketing expenses of large-scale sporting goods manufacturers in China are huge. However, in recent years, the commercial value of sports event IP in China has gradually returned to rationality. The contradiction between high sponsorship fees and low marketing conversion rate has become increasingly prominent. Li-Ning issued an astronomical fine of CNY5.42 million to CBA in October 2020 because of problems such as players' wearing. Facing the high cost of product design to sales, small and medium-sized sporting goods manufacturing industry in China often makes profits by imitating the products of well-known international and domestic sporting goods manufacturing companies in order to avoid high product design and

ISSN: 0010-8189 
marketing expenses, which not only makes the industry lose its ability to innovate and brings problems like prominent legal disputes, disrespect for intellectual property, and product guarantee, etc., but also brings huge damage to well-known international and domestic sporting goods manufacturing brands. In recent years, as digital marketing has become the mainstream, China's sporting goods manufacturing industry should strengthen the layout of digital marketing. In short, for big brands, the contradiction of high marketing expenses is prominent, while for small and medium-sized enterprises, imitations are rampant, and at the same time they are facing new digital marketing trends. China's sport manufacturing industry does not have too many choices on the marketing, and the reform should be accelerated.

\section{Countermeasures for the Transformation and Upgrading of China's Sporting Goods Enterprises}

\subsection{Platform building to attract consumers and meet their personalized customization needs}

The diversified development of consumption demand requires the establishment of a platform for consumer demand. It is essential for creating customer experience under " $\mathrm{C} 2 \mathrm{M}$ " mode. $\mathrm{C} 2 \mathrm{M}$ is essentially based on the industrial Internet. The customer-end should be realized through the use of new digital technology to meet the individual needs of consumers through the deep integration of online and offline. Online platforms allow consumers to choose the core elements of products such as fabrics, colors, sizes, materials, etc. in the form of websites and apps. Offline platforms use 3D sensors, AR, VR and other emerging technologies to obtain consumer basic information. Online and offline information integrate with each other to achieve the uniqueness of each product. When acquiring massive amounts of consumer personalized demand data, the big data obtained is used to form large-scale personalized customization, which makes the consumer's personalized demand more accurate and forms a positive cycle. For example, the Speed Factory established by Adidas makes models by using 3D scanning of the consumers'feet to achieve personalized customization for sports shoes. If China's sporting goods manufacturing industry wants to build its own demand platform to attract consumers, it must examine the three industrial mode under "C2M" mode: r4elying on the large number of consumer demand groups on traditional e-commerce platforms and becoming a link in the upstream industrial chain of those; entering into the vertical e-commerce platform, striving to improve the ODM capabilities of the sporting goods manufacturing industry, and attracting consumers on the platform through products; establishing its own consumption platform, integrating the upper and lower ends of the industrial chain to realize the entire industrial chain. China's sporting goods manufacturing industry should rely on the company's own advantages, disadvantages and opportunities and threats in the external environment to choose a suitable way to establish a consumer demand platform.

\subsection{Building a flexible production chain and changing companies' business management concept}

China is the only country in the world that has all the industrial sectors listed in the industrial classification of United Nations, which shows that China has a huge advantage in the manufacturing sector. The biggest problem of the "C2M" mode is how to build a flexible industrial chain in China's sporting goods manufacturing industry and digitally transform the traditional industrial chain. Emerging technologies such as sensors and edge computing can be used to fully perceive industrial elements, industrial processes, and industrial scenarios to complete the "digitalization" of the industrial chain; connecting industrial factors like personnel, finance, resources, production, raw material, sales and inventory can help realize raw material, research \& development, production, management, fianace and marketing to complete the internetization of the industrial chain; and finally, relying on big data and artificial intelligence will help complete the "intelligentization" of the industrial chain. The core of digitization, internetization and intelligenization lies in the fact that China's sporting goods manufacturing industry must build its own data platform, realize the more modular and synergistic industrial chain, and finally form a flexible industrial chain. The essence of the flexible industrial chain is to reduce production costs and improve production efficiency. However, the high cost of transformation and upgrading makes China's sporting goods manufacturing industry fall behind. Not understanding, being afraid and not trying has made it difficult for China's sporting goods manufacturing industry to create a flexible industrial chain. Meanwhile, the organizational structure, talent reform,

ISSN: 0010-8189

C CONVERTER 2020

www.converter-magazine.info 
Volume 2021, No. 4

and performance management of the enterprise will change with the change of industrial chain. Therefore, in addition to solving the technical key problems for the flexible production chain, it is more important to change the operation and management ideas of China's sports goods manufacturing industry, abandon the traditional management thinking, and make the superstructure more suitable for the development of productivity led by digits.

\subsection{Accelerating the digital management transformation and improving the level of management modernization}

The traditional industrial chain that integrates raw materials, auxiliary materials, production equipment, mechanical parts, research \& development and design, procurement, production and sales will restructure under the "C2M" mode. Under the traditional mode, there are changes of products from the production to sales, which means that manufacturing moves to customer driven by experience thinking. While under " $\mathrm{C} 2 \mathrm{M}$ "mode, relying on the large amount of real-time data generated by the customers, customers moves to manufacturing driven by data thinking. From the M-end first to the $\mathrm{C}$-end first, the circulation of products is accelerated, and the product inventory disappears. Behind those is the digital transformation of management methods. China's sporting goods manufacturing industry needs to focus on three aspects' data elements when carrying out management digitization. Starting from research and design, using industrial design software such as CAD, CAE, CAM, PDM, PLM, EAD, is mainly to improve product development efficiency and reduce development costs; starting from production control, using industrial production software such as MES, APS, SCADA, DSC, is to improve the supervision level of the product process, improving the efficiency of production equipment and production quality; starting from the information management of enterprise, using industrial information software such as ERP, CRM, SCM, HRM, EAM, etc., is to improve the management level of the enterprise, increase the efficiency of information collaboration, and reduce the management cost. Through energizing all data in the entire product chain, the management level is flattened and modernized, the circulation of industrial production to sales is accelerated, and the efficiency of management in all aspects is improved, changing the traditional factory into a smart factory relying on digital transformation.

\subsection{Enhancing brand awareness and pursuing market segmentation}

Under the "C2M" mode, consumers' needs are instant, spontaneous and personalized. In view of the high marketing costs of China's large-scale sporting goods manufacturing industry and the dilemma of small and medium-sized sporting goods manufacturing industry that do not emphasize innovation, corresponding changes will also occur under the "C2M" mode. Because consumers' needs are instant, spontaneous, and personalized, for China's large-scale sporting goods manufacturing industry that is facing the contradiction between huge marketing expenses and inefficient conversion rates, the author believes that the past product marketing should be shifted to branding marketing and digital marketing, improving the brand popularity, reputation and loyalty of large-scale sporting goods companies in China. According to the top 100 global brands in 2020 released by the world-renowned brand evaluation agency Interbrand, Nike and Adidas ranked 15th and 50th respectively as sporting goods companies. Although there are well-known companies such as Li Ning and Anta in China, they were not on the list, which caused a situation that they are large but not strong. As for the digital transformation of the small and medium-sized sporting goods manufacturing industry in China, under the " $\mathrm{C} 2 \mathrm{M}$ " mode, consumers' choosing their individual needs through offline and online platforms is a process of product innovation. Taking advantage of the flexibility of small and medium-sized enterprises, when responding to consumers' individual needs, they should pay more attention to product differentiation, seek a more vertical and segmented market, and occupy their own market share. By concessing profit to consumers, reputation effect is formed to spread the company's popularity, reputation and loyalty so that new vitality can be given to small and medium sporting goods manufacturing.

\section{Conclusion and Suggestion}

ISSN: 0010-8189 


\subsection{Conclusion}

Digital transformation of sporting goods manufacturing industry in China often faces many problems. From the perspective of demand, the existing economic basis for individualized consumer demand makes China's sporting goods manufacturing industry pay attention to the new needs of consumers; from the perspective of production, being in a low value chain, high labor costs, and the erratic price of raw materials since the outbreak of COVID-19 makes China's sporting goods manufacturing industry have to confront new challenges; from the perspective of circulation, the industry's production-to-sales time span is large and risks are high. With the emergence of new retailing, the shortcomings of traditional production and sales mode have gradually become prominent; from the perspective of marketing, the high marketing expenses not only bring a certain burden to China's large-scale sporting goods manufacturing industry, but also poses many risks for innovation of China's small and medium-sized sporting goods manufacturing industry.

\subsection{Countermeasures}

Based on the "C2M" mode, China's sporting goods manufacturing industry has proposed new solutions in four aspects: demand, production, circulation and marketing. In response to the diversification of consumer demand, online and offline platforms must be established to meet the needs of consumers' personalized customization; for the increase in the cost of various factors from the perspective of production, the production chain should be digitized, networked, and intelligentized to reduce production costs and improve production efficiency; in view of the limitations of product design to the sales and circulation, industrial Internet software should be used to carry out digital management transformation and improve the level of management modernization; in view of the huge marketing expenses brought by marketing and the small and medium-sized enterprises not paying attention to innovation, China's large-scale sporting goods manufacturing industry should emphasize on brand building, and the small and medium-sized sporting goods manufacturing industry should pursue the consumer market segmentation.

\section{References}

[1] X.Q. Wang, "New retailing: new changes and new opportunities in retail industry," Beijing, China Economic Publishing House, 2018.

[2] S.M. Zhao, X.H. Xu, "The meaning, mode and development path of "new retailing"," China Business and Market, vol. 31, no. 5, pp. 12-20, 2017.

[3] Z.H. Yan, L. Liu, "The concept, research framework and development trend of "new retailing"," China Business and Market, vol. 31, no. 10, pp. 12-19, 2017.

[4] Y.W. Zhang, "Research on the development trend of traditional retail industry based on the "new retail" Mode," Business Economics, no.3, pp. 84-85, 2018.

[5] J.Z. Yang, "Research on the transformation and upgrading of traditional retail enterprises in china under the background of "new retailing"," Contemporary Economic Management, no. 6, pp. 10-12, 2018.

[6] Z.Y. Zhu, "Research on the strategic transformation of retail enterprises under the new retailing model," Northern Economy and Trade, no. 8, pp. 32-33, 2017.

ISSN: 0010-8189

(c) CONVERTER 2020 